\title{
Parameter Identification of an Induction Motor Drive with Magnetic Saturation for Electric Vehicle
}

\author{
Yu-Seok Jeong ${ }^{\dagger}$ and Jun-Young Lee* \\ $\dagger *$ Dept. of Electrical Eng., Myongji University, Yongin, Korea
}

\begin{abstract}
This paper presents a simulation model and a parameter identification scheme of an induction motor drive for electric vehicle. The induction motor in automotive applications should operate in very high efficiency and achieve the maximum-torque-per-ampere (MTPA) feature even with saturated magnetic flux under very high torque. The indirect vector control which is typically adopted in traction drive system requires precise information of motor parameters, particularly rotor time constants. This work models an induction motor considering magnetic saturation and proposes an empirical identification method using the current controller in the synchronous reference frame. The proposed method is applied to a $22 \mathrm{~kW}$-rated induction motor for electric vehicle.
\end{abstract}

Key Words: Electric vehicle, Induction motor, Magnetic saturation, Parameter identification, Simulation model

\section{INTRODUCTION}

Electric Vehicle (EV) typically employs a permanent magnet (PM) synchronous machine for propulsion owing to its high efficiency and wide operating range under size and weight restrictions. As car companies race to improve electric and hybrid vehicles, their reliance on metals like neodymium used in motors and lithium used in batteries found in electric and hybrid cars, is raising a host of new geopolitical issues over access to the minerals. It is believed to be near a breakthrough in developing electric motors for hybrid cars that eliminates the use of rare earth metals, whose prices have risen sharply in the past year as China restricted their supply [1]. Toyota is striving to develop a different type of electric motor to escape a simmering trade conflict involving China's grip on a rare mineral, and an induction motor is revisited for high power, e.g. electric vehicle and fuel cell vehicle.

While the space angle between the rotor flux vector and the stator d-axis of the stator in a PM synchronous motor can be directly measured, that of an induction motor is not a directly measureable quantity and thus it is more difficult to control. With the rotor-flux-oriented control there are two main implementations to obtain the space angle of the rotor flux vector [2]. In flux feedback control, so called direct vector control, it is calculated from the measured or estimated stator flux. In flux feedforward control, so called indirect vector control, it is obtained by adding the electrical rotor angle and the slip angle which strongly depends on the rotor time constant. The rotor time constant is equal to the ratio of the

\footnotetext{
Manuscript received Feb. 5, 2011; revised May 19, 2011

Recommended for publication by Guest Associate Editor Byoung-Kuk Lee.

$\dagger$ Corresponding Author: jeong@mju.ac.kr

Tel: +81-31-330-6363, Fax: +82-31-321-0271, Myongji University

* Dept. of Electrical Eng., Myongji University, Korea
}

rotor inductance varying with magnetizing current to rotor resistance varying with temperature. Numerous researches have discussed identification algorithm of the rotor parameters by either on-line or off-line [3]-[7]. Despite its parameter sensitivity, the indirect vector control has gained more widespread for automotive applications where the maximum torque should be produced even at standstill.

Efficiency of electric drives is a crucial index for automotive applications due to a limited power source, e.g. a battery/a fuel cell. The maximum-torque-per-ampere (MTPA) operation is preferred rather than the rated flux operation common for industrial drives [8]. The electric motors for vehicle are typically designed in very compact size allowing higher flux level than rated and often experience magnetic saturation.

This work proposes an identification scheme of motor parameters using the dq-axis equivalent circuit in the synchronous reference frame rather than the conventional single-phase equivalent circuit. The simulation model of an induction motor considering magnetic saturation using Matlab/Simulink ${ }^{\circledR}$ is also developed to evaluate its control dynamics. The proposed method is applied to a $22 \mathrm{~kW}$-rated induction motor which is proper for compact-sized electric vehicle.

\section{Mathematical Model of An Induction Motor INCLUDING MAGNETIC SATURATION}

The stator and rotor voltage equations of an induction motor in the synchronous reference frame neglecting iron losses can be expressed in the complex vector form as

$$
\begin{aligned}
\vec{v}_{d q s}^{e} & =R_{s} \vec{i}_{d q s}^{e}+\frac{d}{d t} \vec{\lambda}_{d q s}^{e}+j \omega_{e} \vec{\lambda}_{d q s}^{e} \\
0 & =R_{r} \vec{i}_{d q r}^{e}+\frac{d}{d t} \vec{\lambda}_{d q r}^{e}+j\left(\omega_{e}-\omega_{r}\right) \vec{\lambda}_{d q r}^{e}
\end{aligned}
$$




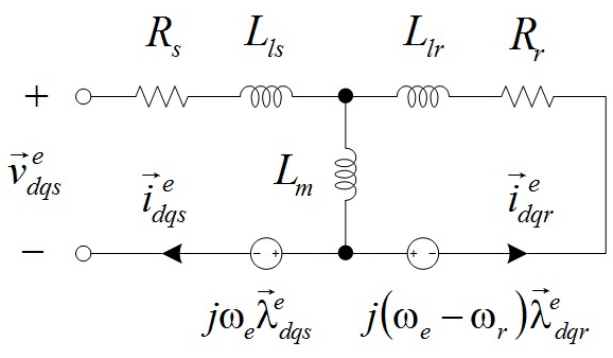

Fig. 1. $d-q$ winding model of a cylindrical PMSM.

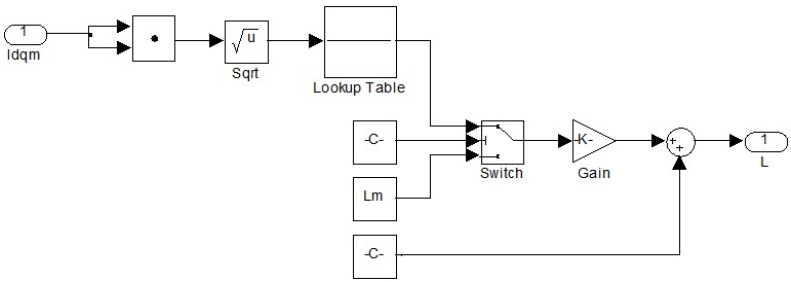

Fig. 2. Inductance model considering magnetic saturation.

where the superscript e and s denotes the synchronous and the stationary reference frame respectively, and the subscript $\mathrm{d}$, q, $\mathrm{s}$ and $\mathrm{r}$ denote the $\mathrm{d}$-axis, the $\mathrm{q}$-axis, the stator, and the rotor, respectively.

The stator and rotor flux linkage vectors in the synchronous reference frame can be expressed in terms of the stator and rotor current vector as

$$
\begin{aligned}
& \vec{\lambda}_{d q s}^{e}=\left(L_{l s}+L_{m}\right) \vec{i}_{d q s}^{e}+L_{m} \vec{i}_{d q r}^{e}=L_{s} \vec{i}_{d q s}^{e}+L_{m} \vec{i}_{d q r}^{e} \\
& \vec{\lambda}_{d q r}^{e}=\left(L_{l r}+L_{m}\right) \vec{i}_{d q r}^{e}+L_{m} \vec{i}_{d q s}^{e}=L_{r} \vec{i}_{d q r}^{e}+L_{m} \vec{i}_{d q s}^{e}
\end{aligned}
$$

The electromagnetic torque for rotor-flux-oriented control can be expressed as

$$
\tau_{e}=\frac{3}{2} \frac{P}{2} \frac{L_{m}}{L_{r}}\left(\lambda_{d r}^{e} i_{q s}^{e}-\lambda_{q r}^{e} e_{d s}^{e}\right)
$$

The equivalent circuit of an induction motor based on (1) and (2) is depicted in Fig. 1.

Assuming saturation of the main flux paths, the magnetizing inductance and thus the stator and rotor inductances are not constant but vary with saturation. The magnetizing inductance can be expressed as a function of the modulus of the magnetizing current vector. The inductance matrix considering magnetic saturation in Simulink ${ }^{\circledR}$ can be modeled as depicted in Fig. 2.

Based on the switch selection, the linear model uses a constant magnetizing inductance and the saturated model uses a varying inductance from the look-up table whose input is the modulus of the magnetizing current vector.

The voltage equation of an induction motor can be modeled in Simulink ${ }^{\circledR}$ as shown in Fig. 3. It should be noted that the synchronous angle should be calculated using the atan function and fed back to transform the stator voltage to the synchronous reference frame using a memory block to avoid the algebraic loop error. Therefore, it is more convenient to build the electrical model of an induction machine in the stationary reference or in the rotor reference frame as depicted in Fig. 3. In this case, an additional transformation using the slip angle is needed to display the electrical variables in the synchronous reference frame.
For the rotor-flux-oriented control, the q-axis rotor flux linkage is zero since the rotor flux vector is fixed to the daxis of the synchronous reference frame. The rotor voltage equation in (1) can be simplified as

$$
\begin{gathered}
\frac{L_{r}}{R_{r}} \frac{d}{d t} \lambda_{d r}^{e}+\lambda_{d r}^{e}=L_{m} i_{d s}^{e} \\
\omega_{e}=\omega_{r}+\frac{R_{r}}{L_{r}} \frac{L_{m} i_{q s}^{e}}{\lambda_{d r}^{e}}
\end{gathered}
$$

where the ratio of the rotor inductance to the rotor resistance is defined as the rotor time constant, which is not actually a constant but a parameter varying with temperature and saturation.

The angle for the transformation between the stationary and the synchronous reference frame in the indirect vector control can be calculated from the angular slip frequency in (5).

\section{PARAMETER MEASUREMENT}

Various methods have been researched for obtaining the electrical parameters of the induction motor. Traditionally, these parameters can be obtained by performing the no-load and locked-rotor tests and this work proposes a test method using the current controller in the synchronous reference frame already designed for torque control.

The voltage equation in steady state and the rotor current vector and the rotor flux linkage vector can be expressed with the stator current vector and the stator flux linkage vector as

$$
\begin{aligned}
{\left[\begin{array}{c}
\vec{v}_{d q s}^{e} \\
0
\end{array}\right] } & =\left[\begin{array}{cc}
R_{s} & 0 \\
0 & R_{r}
\end{array}\right]\left[\begin{array}{l}
\vec{i}_{d q s}^{e} \\
\vec{i}_{d q r}^{e}
\end{array}\right]+\left[\begin{array}{cc}
j \omega_{e} & 0 \\
0 & j\left(\omega_{e}-\omega_{r}\right)
\end{array}\right]\left[\begin{array}{l}
\vec{\lambda}_{d q s}^{e} \\
\vec{\lambda}_{d q r}^{e}
\end{array}\right] \\
{\left[\begin{array}{c}
\vec{\lambda}_{d q r}^{e} \\
\vec{i}_{d q r}^{e}
\end{array}\right] } & =\frac{1}{L_{m}}\left[\begin{array}{cc}
L_{r} & -\sigma L_{s} L_{r} \\
1 & -L_{s}
\end{array}\right]\left[\begin{array}{l}
\vec{\lambda}_{d q s}^{e} \\
\vec{i}_{d q s}^{e}
\end{array}\right] \\
\sigma & =1-\frac{L_{m}^{2}}{L_{s} L_{r}}
\end{aligned}
$$

where $\sigma$ denotes the leakage factor.

Substitution of the rotor current and flux linkage vector into the voltage equation in (6) finally gives

$$
\vec{v}_{d q s}^{e}=\left\{R_{s}+j \omega_{e} L_{s} \frac{R_{r}+j\left(\omega_{e}-\omega_{r}\right) \sigma L_{r}}{R_{r}+j\left(\omega_{e}-\omega_{r}\right) L_{r}}\right\} \vec{i}_{d q s}^{e}
$$

For rotor-flux-oriented control, a current vector with the amplitude of $I^{*}$ and the frequency of $\omega_{e}^{*}$ can be expressed as

$$
\begin{aligned}
\vec{i}_{d q s}^{e} & =I^{*} e^{j \tan ^{-1} \frac{L_{r}}{R_{r}}\left(\omega_{e}^{*}-\omega_{r}\right)} \\
i_{d s}^{e} & =I^{*} \frac{R_{r}}{\sqrt{R_{r}^{2}+\left(\omega_{e}^{*}-\omega_{r}\right)^{2} L_{r}^{2}}} \\
i_{q s}^{e} & =I^{*} \frac{\left(\omega_{e}^{*}-\omega_{r}\right) L_{r}}{\sqrt{R_{r}^{2}+\left(\omega_{e}^{*}-\omega_{r}\right)^{2} L_{r}^{2}}}
\end{aligned}
$$




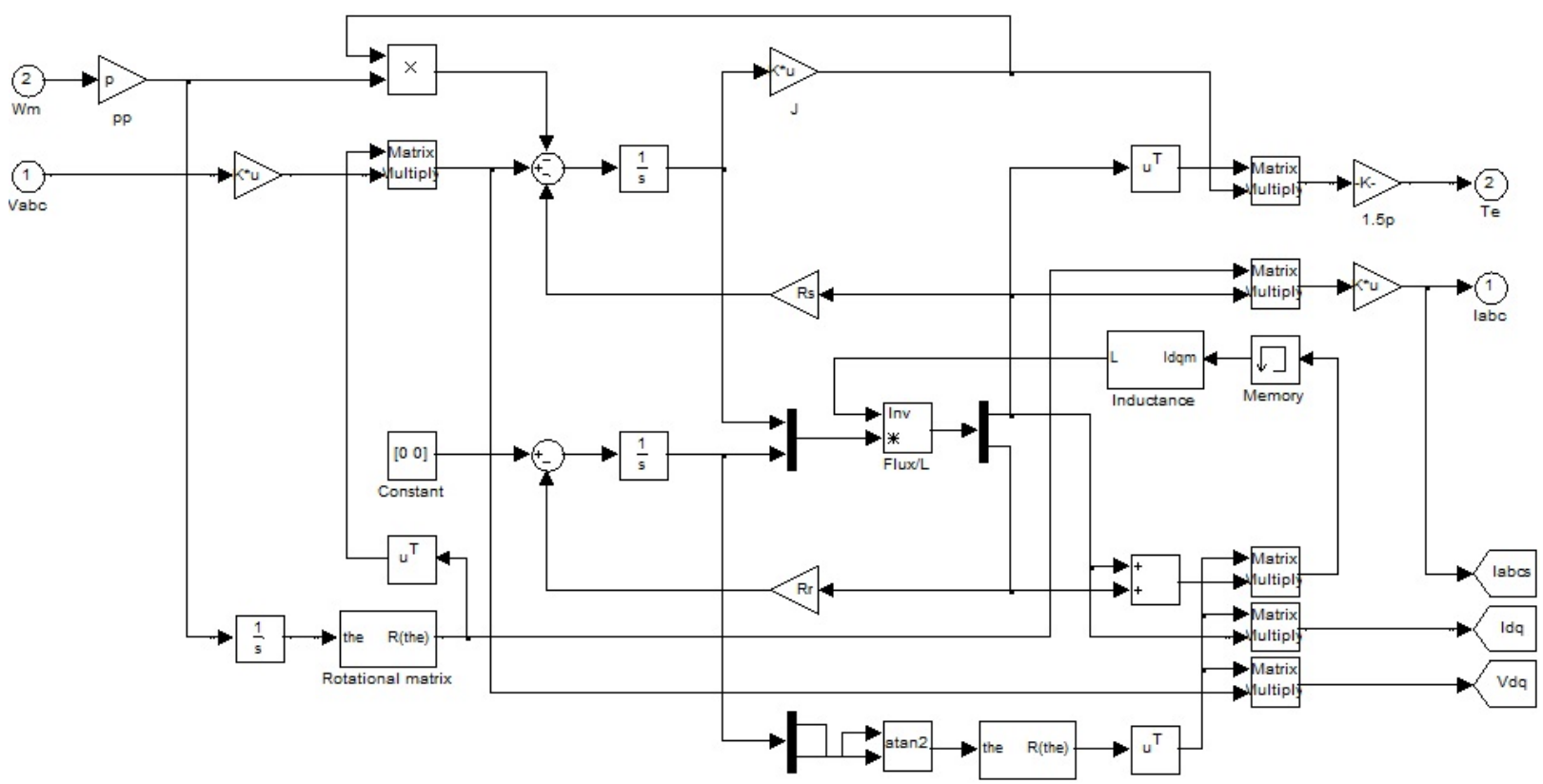

Fig. 3. Simulink ${ }^{\circledR}$ model of an induction motor in the rotor reference frame.

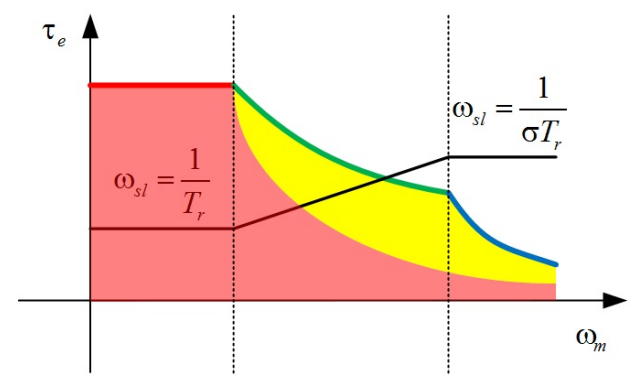

Fig. 4. capability curve of an induction motor.

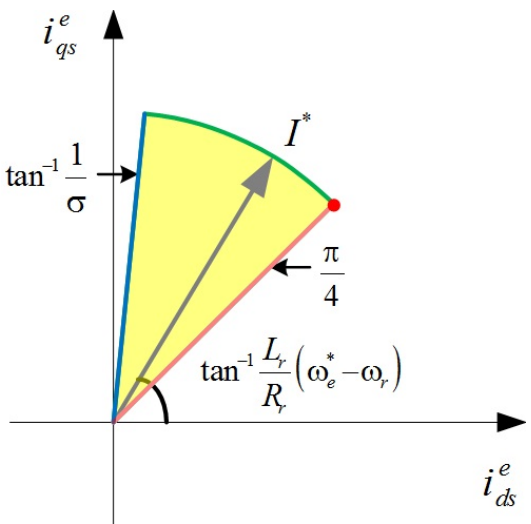

Fig. 5. current vector in the synchronous reference frame.

A. Current vector along the d-axis in the synchronous reference frame at rated speed (no load test)

When the slip frequency is zero, i.e. the excitation frequency is equal to the electrical rotor speed, the q-axis current in (8) becomes zero and the stator voltage in (7) can be simplified as

$$
\vec{v}_{d q s}^{e}=\left(R_{s}+j \omega_{e} L_{s}\right) \vec{i}_{d q s}^{e}
$$

Thus, the stator resistance and the stator inductance can be calculated as

$$
R_{s}=\left.\frac{v_{d s}^{e}}{I^{*}}\right|_{\omega_{e}^{*}=\omega_{r}} \quad L_{s}=\left.\frac{v_{q s}^{e}}{\omega_{e}^{*} I^{*}}\right|_{\omega_{e}^{*}=\omega_{r}}
$$

where the stator inductance should be saved at each current level to make a look-up table for the magnetization curve whose input is the d-axis stator current which corresponds to the magnetizing current in the rotor-flux-oriented control.

\section{B. Current vector nearly along the q-axis in the synchronous} reference frame at standstill (locked-rotor test)

When the slip frequency at standstill is high enough to make $R_{r}<<\omega_{e} L_{r}$, the d-axis current in (8) becomes nearly zero and the stator voltage in (7) can be simplified as

$$
\vec{v}_{d q s}^{e}=\left(R_{s}+\frac{L_{s}}{L_{r}} R_{r}+j \omega_{e} \sigma L_{s}\right) \vec{i}_{d q s}^{e}
$$

Thus, the rotor time constant and the leakage factor can be calculated as

$$
\frac{1}{T_{r}}=\left.\frac{R_{r}}{L_{r}} \approx \frac{v_{q s}^{e}-R_{s} I^{*}}{L_{s} I^{*}}\right|_{\omega_{e}^{*}>>\frac{R_{r}}{L_{r}}} \sigma \approx-\left.\frac{v_{d s}^{e}}{\omega_{e}^{*} L_{s} I^{*}}\right|_{\omega_{e}^{*}>>\frac{R_{r}}{L_{r}}} .
$$

It should be noted that regulating the d-axis current to zero, d-axis of this synchronous reference frame does not exactly coincide with the rotor flux vector since the excitation frequency is practically limited.

For the accuracy of estimation, the proposed method to identify the rotor resistance in this work is to take advantage of the active power produced in the induction motor.

The electromagnetic torque in (3) in steady state yields

$$
\begin{aligned}
\tau_{e} & =\frac{3}{2} \frac{P}{2} \frac{L_{m}^{2}}{L_{r}} i_{d s}^{e} i_{q s}^{e} \\
& =\frac{3}{2} \frac{P}{2} \frac{L_{m}^{2}}{L_{r}} I^{* 2} \sin \left\{2 \tan ^{-1} \frac{L_{r}}{R_{r}}\left(\omega_{e}^{*}-\omega_{r}\right)\right\}
\end{aligned}
$$


TABLE I

MOTOR SPECIFICATIONS

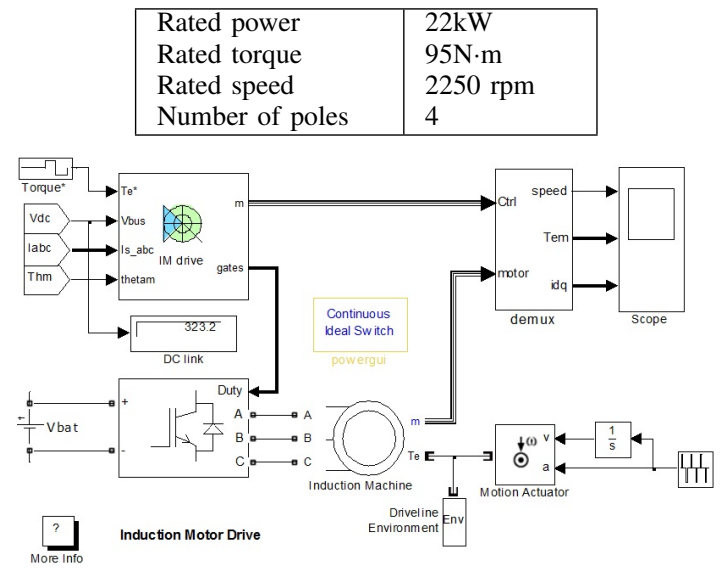

Fig. 6. simulation model of an induction motor drive.

which will have its maximum when the $\mathrm{d}$-axis and q-axis currents are equal to each other with a fixed amplitude. This condition can be monitored not only by measuring directly the produced torque but also by calculating the electric power supplied to the induction motor at the constant operating speed.

The electric power calculated with the stator voltage and the stator current vector in steady state can be expressed as

$$
\begin{aligned}
p_{e} & =\frac{3}{2} \vec{v}_{d q s}^{e} \cdot \vec{i}_{d q s}^{e}=\frac{3}{2}\left(R_{s} \vec{i}_{d q s}^{e}+j \omega_{e}^{*} \vec{\lambda}_{d q s}^{e}\right) \cdot \vec{i}_{d q s}^{e} \\
& =\frac{3}{2}\left\{R_{s}+\frac{\omega_{e}^{*}\left(\omega_{e}^{*}-\omega_{r}\right) L_{m}^{2} R_{r}}{R_{r}^{2}+\left(\omega_{e}^{*}-\omega_{r}\right)^{2} L_{r}^{2}}\right\} I^{* 2}
\end{aligned}
$$

The excitation frequency for the peak electric power can be obtained by its differentiation in (14) with respect to the excitation frequency, and setting this 1st derivative to zero. This yields

$$
\begin{aligned}
\omega_{e}^{*} & =\omega_{r}+\left.\frac{R_{r}}{L_{r}}\left\{\frac{1}{\omega_{r}}+\sqrt{1+\left(\frac{R_{r}}{\omega_{r} L_{r}}\right)^{2}}\right\}\right|_{\frac{\partial p_{e}}{\partial \omega_{e}^{*}}=0} \\
& \approx \omega_{r}+\frac{R_{r}}{L_{r}}=\omega_{r}+\frac{1}{T_{r}}
\end{aligned}
$$

It should be noted that the rotor time constant in (15) should be compensated with the variation of temperature and saturation. Thus two look-up tables whose inputs are temperature and the d-axis stator current respectively are required to adjust the rotor time constant.

As the induction motor moves through the flux weakening region, the slip frequency increases from the reciprocal of the rotor time constant in (15) to the breakdown value to

$$
\omega_{s l_{-} \max }^{*}=\omega_{e}^{*}-\omega_{r}=\frac{R_{r}}{L_{r}} \frac{i_{q s}^{e}}{i_{d s}^{e}}=\frac{R_{r}}{L_{r}} \cdot \frac{1}{\sigma}=\frac{1}{\sigma T_{r}} .
$$

\section{Simulations AND EXPERIMENTS}

The parameter estimation scheme of an induction motor has been investigated by computer simulations. Simulink ${ }^{\circledR}$ was used for the computer simulation. The specifications of the induction motor tested in this work are listed in Table I.

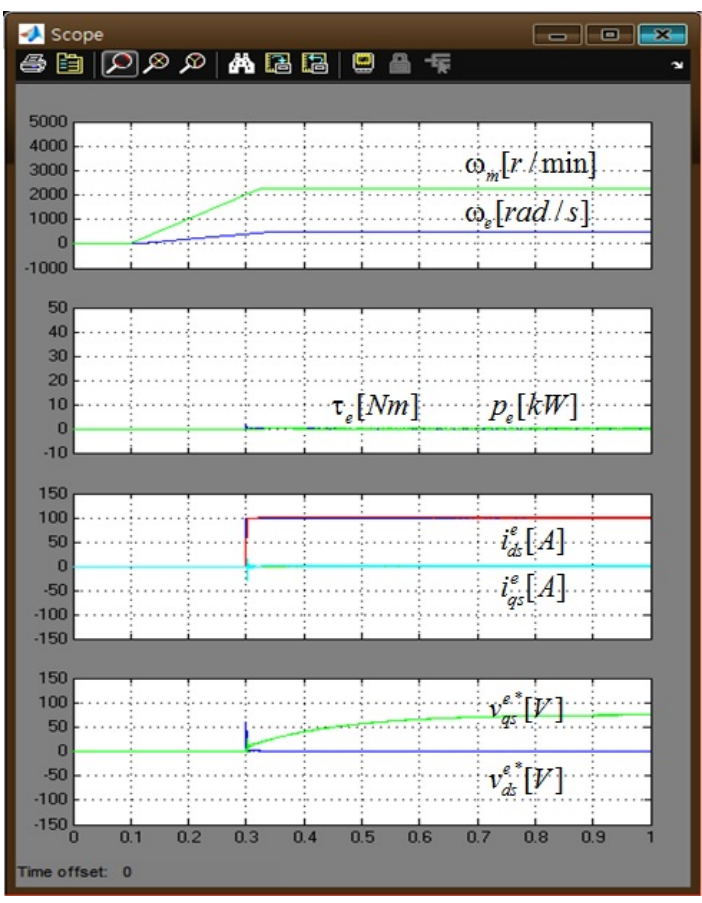

Fig. 7. no-load simulation of the induction motor drive.

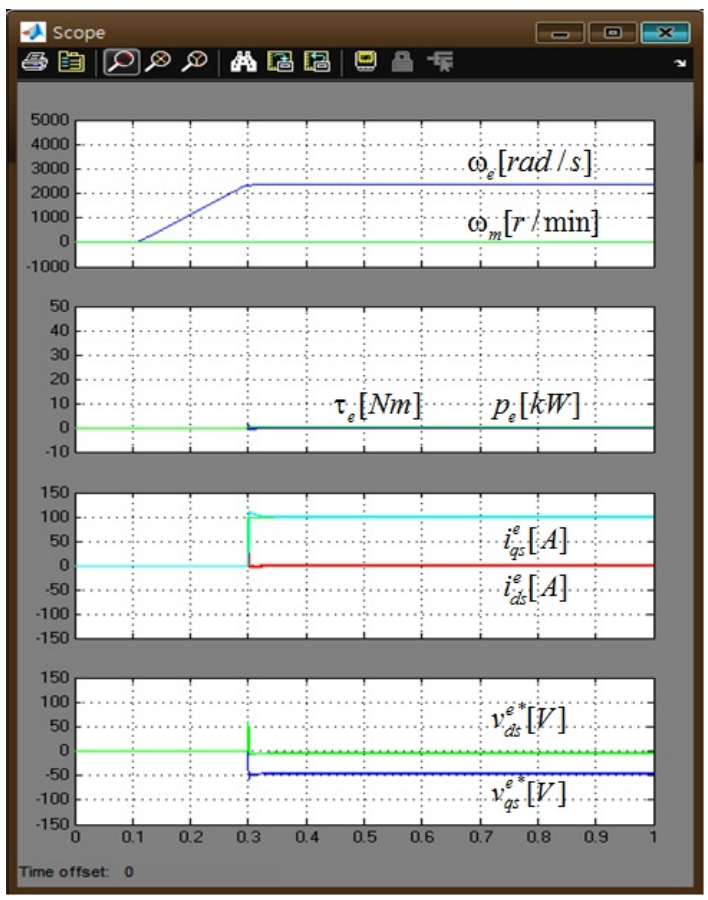

Fig. 8. locked-rotor simulation of the induction motor drive.

The induction motor is operated by a dynamometer at the rated speed of $2250 \mathrm{r} / \mathrm{min}$ corresponding to the electrical frequency of $75 \mathrm{~Hz}$ for no-load test. The d-axis current reference of $100 \mathrm{~A}$ corresponding to the rated magnetizing current is applied to the current controller as shown in Fig. 7. It can be seen that the transient response of the q-axis voltage is caused by the $\mathrm{d}$-axis rotor flux linkage.

The locked-rotor simulation result is depicted in Fig. 8, where the excitation frequency is practically chosen as the electrical frequency of $375 \mathrm{~Hz}$ corresponding to the maximum speed of $11250 \mathrm{r} / \mathrm{min}$. The q-axis current reference of $100 \mathrm{~A}$ is 


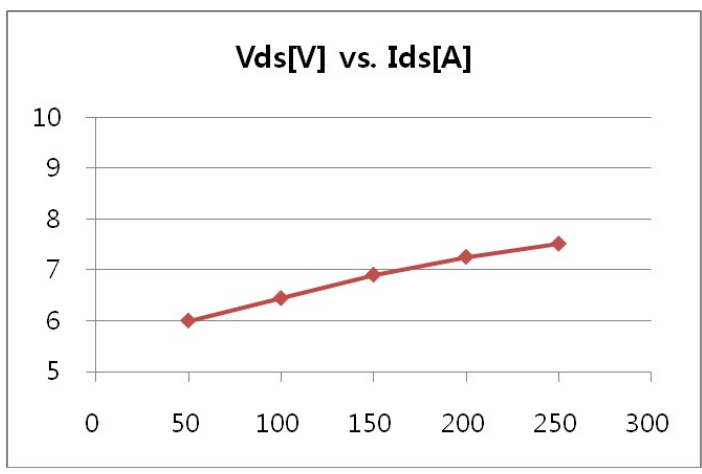

Fig. 9. d-axis stator voltage vs. d-axis stator current.

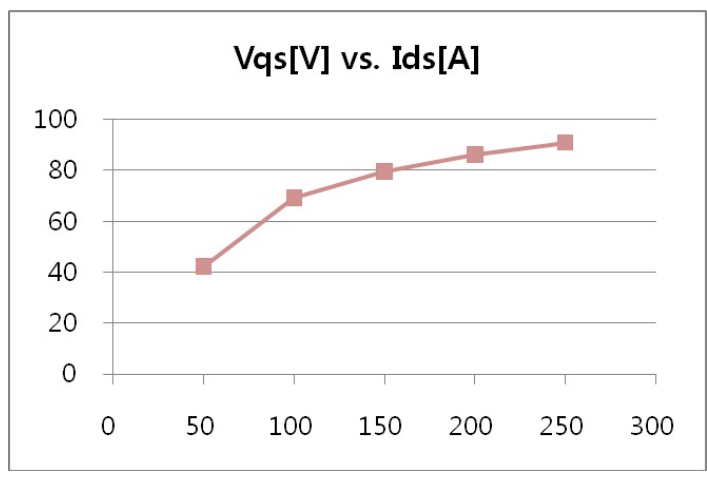

Fig. 10. q-axis stator voltage vs. d-axis stator current.

applied to the current controller and it can be seen that the transient response of the d-axis voltage is much faster than that of the q-axis at no-load test since the q-axis rotor flux linkage is zero in the rotor flux oriented control.

The induction motor in Table I is tested for the stator parameter identification at the rated speed of $2250 \mathrm{r} / \mathrm{min}$ without q-axis current command and the stator voltage references of the current controller designed in the synchronous reference frame are depicted in Fig. 9 and Fig. 10.

The d-axis voltage on the output of the current controller is ideally proportional to the d-axis current at no load without the voltage drop of the power device. To obtain a correct value of the stator resistance, it is recommended to utilize two test points instead of the origin.

The q-axis voltage on the output of the current controller is also proportional to the d-axis current at no load without magnetic saturation. The stator inductance proportional to the slope of the q-axis voltage decreases as the d-axis current increases as shown in Fig. 11.

$$
\begin{gathered}
R_{s}=\frac{\Delta v_{d s}^{e}}{\Delta I^{*}}=\frac{v_{d s}^{e}\left(I_{2}^{*}\right)-v_{d s}^{e}\left(I_{1}^{*}\right)}{I_{2}^{*}-I_{1}^{*}} \\
L_{s}=\frac{v_{q s}^{e}\left(I_{1}^{*}\right)}{\omega_{e}^{*} I_{1}^{*}}, \cdots, \frac{v_{q s}^{e}\left(I_{n}^{*}\right)}{\omega_{e}^{*} I_{n}^{*}} .
\end{gathered}
$$

The induction motor is tested for the rotor parameter identification at standstill without d-axis current command and the $\mathrm{d}$-axis stator voltage reference is depicted in Fig. 12, where the excitation frequency is chosen as the electrical frequency of $375 \mathrm{~Hz}$. The locked-rotor test gives the leakage factor from

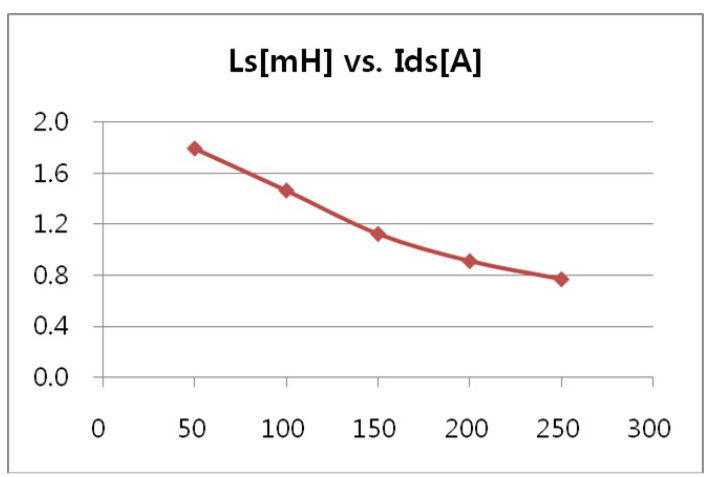

Fig. 11. stator inductance vs. d-axis stator current.

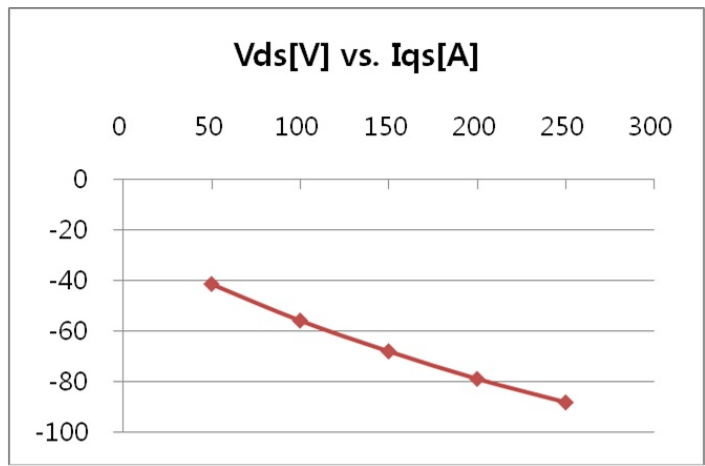

Fig. 12. d-axis stator voltage vs. q-axis stator current.

the q-axis stator flux linkage as

$$
\sigma=-\frac{v_{d s}^{e}}{\omega_{e}^{*} L_{s} I^{*}} .
$$

It should be noted that the leakage factor highly depends on the skin effect and can be measured by using the frequency characteristics [9].

The magnetizing inductance can be calculated from the stator inductance and the leakage factor assuming that the stator leakage and the rotor leakage inductances are equal to each other. It is stored in the look-up table in Fig. 2 to take magnetic saturation into account during operation.

$$
L_{m}\left(i_{d s}^{e}\right)=L_{s}\left(i_{d s}^{e}\right)-L_{l s}\left(i_{d s}^{e}\right) \approx\left(1-\frac{\sigma}{2}\right) L_{s}\left(i_{d s}^{e}\right) .
$$

The induction motor is tested for the rotor time constant identification at the rated speed with the varying excitation frequency for the electric power is shown in Fig. 13.

The rotor time constant can be calculated from the angular slip frequency which makes the electrical power at its maximum. The rotor time constant should be adjusted with temperature and magnetic saturation.

$$
T_{r}=\left.\frac{1}{\omega_{e}^{*}-\omega_{r}}\right|_{\max p_{e}} .
$$

\section{CONCLUSIONS}

This paper has introduced a simulation model of an induction motor in rotor reference frame using Simulink ${ }^{\circledR}$ considering magnetic saturation and proposed a parameter identification scheme of the induction motor in steady state using the current controller designed for torque control in the synchronous reference frame. The proposed identification 


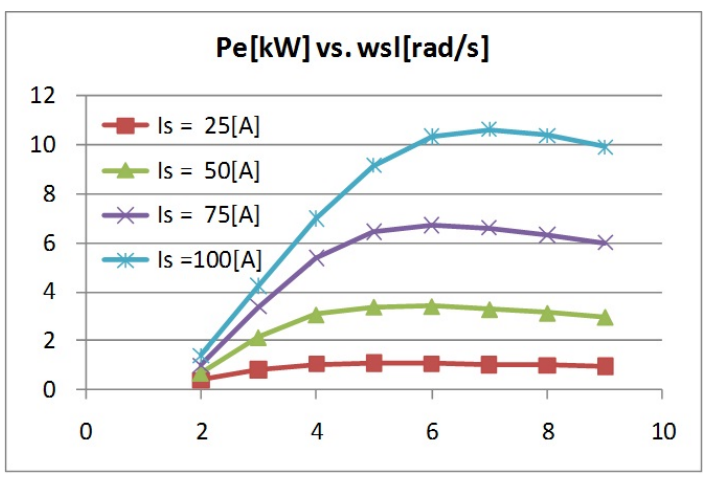

Fig. 13. electric power vs. slip frequency.

scheme consists of the no-load test at the rated speed for the identification of the stator parameters, the locked-rotor test at standstill for the identification of the leakage factor and the peak-power test for the identification of the rotor time constant. Future work on the identification method of the rotor time constant variation due to temperature could be helpful to extend this research.

\section{ACKNOWLEDGMENT}

This work was supported by the 2010 research fund of Myongji University in Korea.

\section{REFERENCES}

[1] Anon, China's Complete Control of Global High-Tech Magnet Industry Raises U.S. National Security Alarms, Manufacturing and Technology News, Vol. 16, No. 16, Sep. 2009.

[2] P. Vas, Vector Control of AC Machines, Clarendon Press Oxford, Chap. 4, 1990.

[3] C. Kim, "An on-line rotor resistance estimator for induction machine drives," Journal of Power Electronics, Vol. 9, No. 3, pp. 354-364, May 2009.

[4] M. Hajian, J. Soltani, G. A. Markadeh, and S. Hosseinnia, "Inputoutput feedback linearization of sensorless im drives with stator and rotor resistance estimation," Journal of Power Electronics, Vol. 9, No. 4, pp. 654-666, Jul. 2009.

[5] J. Seok and S. Sul, "Induction motor parameter tuning for highperformance drives," IEEE Trans. on Industry Applications, Vol. 37, No. 1, pp. 35-41, Jan./Feb. 2001.
[6] V. R. Jevremovic, V. Vasic, D. P. Marcetic, and B. Jeftenic, "Speedsensorless control of induction motor based on reactive power with rotor time constant identification," IET Electric Power Applications, Vol. 4, No. 6, pp. 462-473, Jul. 2010.

[7] M. L. Campbell, J. Chiasson, M. Bodson, and L. M. Tolbert, "Speed sensorless identification of the rotor time constant in induction machines," IEEE Trans. on Autom. Control, Vol. 52, No. 4, pp. 758-763, Apr. 2007.

[8] H. Kouns, J. Lai, and C. E. Konrad, "Analysis of a traction induction motor drive operating under maximum efficiency and maximum torque per ampere conditions," in 19th Applied Power Electronics Conference and Exposition, pp. 541-551, 2004.

[9] Y. Kwon, J. Lee, S. Moon, B. Kwon, C. Choi, and J. Seok, "Standstill parameter identification of vector-controlled induction motors using the frequency characteristics of rotor bars," IEEE Trans. on Ind. Appl., Vol. 45, No. 5, pp. 1610-1618, Sep./Oct. 2009.

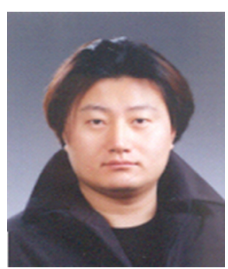

Yu-Seok Jeong was born at Daegu, Korea, in 1971 He received the B.S., M.S., and Ph.D. degrees from Seoul National University, Seoul, Korea, in 1993, 1995, and 2005, respectively, all in electrical engineering. He joined the Kia Motors Technical Center, Seoul, Korea, as a Research Engineer in 1995. In 2001 and 2002, he was a special student at the University of Wisconsin, Madison. During his doctoral course, he pursued faulttolerant control and robust adaptive control of IPM synchronous machine drives in collaboration with GM. Following a year's experience to develop a motor drive system for HEV/FCV applications at Hyundai Motor Company in 2005, he is currently with the Dept. of Electrical Eng., Myongji Univ., Gyeonggi-do, Korea. His research interests include modeling and digital control of power electronics and energy conversion.

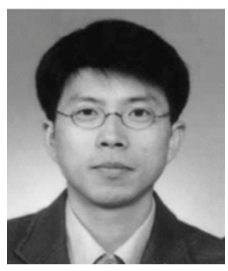

Jun-Young Lee was born in Seoul, Korea in 1970. $\mathrm{He}$ received his B.S. degree in Electrical Engineering from Korea University, Seoul, in 1993 and his M.S and Ph.D. degrees in Electrical Engineering from Korea Advanced Institute of Science and Technology, Taejon, Korea, in 1996 and 2001, respectively. From 2001 to 2005, he worked as a Manager in Plasma Display Panel Development Group, Samsung SDI where he was involved in circuit and product development. From 2005 to 2008 , he worked as a faculty member in the School of Electronics and Computer Engineering, Dankook University, Chungnam, Korea. In 2008, he joined the Department of Electrical Engineering, Myongji University, Gyeonggi-do, Korea, as an assistant professor. His research interests are in the areas of power electronics which include $\mathrm{AC} / \mathrm{DC} /$ power factor correction converter topology design, converter modeling, soft switching techniques, display driving system, and liquid crystal display backlight units. Dr. Lee is a member of the Korea Institute of Electrical Engineering (KIEE), Korea Institute of Power Electronics (KIPE), and the IEEE Industrial Electronics and IEEE Power Electronics Societies. 